\title{
Prediction of the Impact Behavior of Bio-hybrid Composites Using Finite Element Method
}

Davide Mocerino, Luca Boccarusso, Dario De Fazio, Massimo Durante, Antonio Langella, Michele Meo, Fulvio Pinto and Francesco Rizzo

\author{
Davide Mocerino. Department of Chemical Materials and Production Engineering, University of Naples Federico II, Italy \\ Corresponding author: davide.mocerino@unina.it \\ Luca Boccarusso. Department of Chemical Materials and Production Engineering, University of Naples Federico II, Italy \\ Dario De Fazio. Department of Chemical Materials and Production Engineering, University of Naples Federico II, Italy \\ Massimo Durante. Department of Chemical Materials and Production Engineering, University of Naples Federico II, Italy \\ Antonio Langella. Department of Chemical Materials and Production Engineering, University of Naples Federico II, Italy \\ Michele Meo. Material Research Centre, Department of Mechanical Engineering, University of Bath, Bath, UK \\ Fulvio Pinto. Material Research Centre, Department of Mechanical Engineering, University of Bath, Bath, UK \\ Francesco Rizzo. Material Research Centre, Department of Mechanical Engineering, University of Bath, Bath, UK
}

\begin{abstract}
The use of composite hybridization using both synthetic and natural fibers, is one of the most established way to combine the advantages of each material that forms the composite system in order to obtain a composite with good in-plane and out-of-plane properties. For example, as pointed out in authors previous research works, considering carbon/hemp hybrid composites, it is possible to combine the ductile behavior and the capacity to absorb energy of hemp fibers with the higher strength and stiffness of carbon allowing the development of a hybrid system with enhanced energy absorption capability, reduced production cost and lower environmental impact respect to traditional carbon fibers composites. The aim of this work is to investigate both experimentally and numerically the mechanical behavior at impact of pure carbon, pure hemp and carbon/hemp hybrid composite laminate. Low velocity impact tests at $10 \mathrm{~J}$ and $20 \mathrm{~J}$ were carried and non-destructive analyses were performed for each impact energy to evaluate the internal damage extent. The same tests were numerically simulated with LS-DYNA software using shell elements and different material cards (i.e. MAT 54/55, MAT 24 depending on typology of fibers) and contact conditions in order to find the best configuration that matches the experimental results.
\end{abstract}

Keywords. Hemp Fibers, Hybrid Composites, Numerical Simulation, LS-dyna

\section{Introduction}

Fibre reinforced plastics (FRPs) composites are a widely used family of materials that exhibit high mechanical properties without sacrificing the necessity of lightweight. This aspect makes them very attractive for different applications in industrial fields like automotive [1], naval, aerospace [2], sporting goods and so on. Respect to traditional materials, composite structures are characterized by a large number of options in terms of design and manufacturing techniques to combine fibres and matrix allowing a high level of tailorability and then a high design customization. This design of freedom is reflected in the choice of dimension and type of fibers and matrices, fibers orientation and content fraction, and stacking sequence. This means that there is the possibility to incorporate within the same matrix system, two or more fiber types in order to obtain final products with unique characteristics. The composite systems resulting from this interaction are known as fiber-hybrid composites (FHCs) and their main advantages are to exploit the best characteristics of each component and at the same time to alleviate the inherent drawbacks of each one. Considering carbon fibers composites, it is well known that on one hand these composite systems are characterized by high stiffness, flexural and tensile strength but on the other hand they have some drawbacks like the high cost, the brittle behavior and the low resistance at impact loads. A possible solution to alleviate these disadvantages is the use of 
carbon fibres in a hybrid system with other fibers. The first evidence of hybridized carbon composite was in 70's, when the incorporation of glass fibres into carbon fibre composites was proposed as an appealing technique that allowed not only for the reduction of the production costs but also enabled additional energy dissipation and failure mechanisms as proved by different research works [3-7]. From the faraway 70's, nowadays the new generation of composite systems have to minimize the environmental impact with a more efficient use of energy resources and materials, and waste management, employing new technologies with less environmental impact and, where possible, to replace synthetic or petroleum materials with more eco-sustainable components. In this scenario, a very interesting approach is the replacing of glass fibers with vegetable ones. This is testified by the increasing number of scientific researches works over the last decade that focused their efforts studying the use of vegetable fibers both in hybrid and conventional composite systems [8-13].

It is important to note that carbon/vegetable fibre hybrid composites can be taken into account especially for the possible combination of properties, since vegetable fibre composites might allow different mechanisms of damage propagation and energy dissipation mitigating the inherent brittleness (limited toughness) of carbon fibre composites [14-16]. Indeed, Sarasini et al [17] noted the improvement of damage tolerance of hybridization using a combination of carbon and flax fibers considering different stacking sequences. Also Safri [18], Reddy [19] and Murdani [20] found in hybridization a valid method to improve mechanical behavior due to different internal damage initiation and different evolution of cracking that allowing an improvement of energy absorption.

Flax is the most common vegetable fibers that can be used as reinforcement in hybrid carbon fibers composite materials as testified by Cheng et all. [21] or by Assarar [22], however also hemp lends itself well for the hybridization [14]. Hemp, indeed, is one of the most interesting vegetable fibers due to its active mechanical properties, lower production costs then flax, high cellulose content and its ability to easily grow around the world without requiring specific climatic conditions.

Therefore, in the present work, hemp fibers were used together with carbon fibers in a hybrid system in order to study if the presence of the vegetable fibers can positively affect the weak impact behavior that characterize the carbon composites [23-25]. Indeed, impact is one of the most typical condition that composites materials undergo, furthermore, low velocity impact (LVI) causes in composites laminate large damages as delamination or matrix cracking leaving on surface only small visible traces and a significative decreasing of mechanical properties [26], so LVI results the most typical tests to do for the characterization of composite specimens [27]. As already mentioned, low velocity impact damage may be unnoticed with a visual inspection [28] so there are different Non-Destructive Tests (NDTs) to localize the damage within the laminate [29]. In this context, the use of C-Scan technique is considered one of the most a reliable method to recognize and measure the damaged area [30-32].

In addition, it is expected that the impact behavior can be strictly affected by the relative positions of hemp and carbon layers and then a possible way to design a final product with specific characteristics, without experimentally tested all possible configurations, could be the prediction of composite mechanical properties by using finite elements (FE) simulations [33]. This approach, after inevitable and appropriate validations, does not allow only the prediction of the impact resistance and adsorbed energy but also the prediction of size and position of damages.

Simulating the performance of a hybrid laminate is an open challenge due to their particular response that has to take into account the combined presence of two (or more) different materials having two different behaviors [34]. Different approaches exist to model different typology of fibers, different typology of interlaminar force and different typology of crashing routine. Ramakrishnan [35] used an approach based on a homogenization model, started from a micromechanical approach with Digimat software, to simulate the impact behavior of flax and PP and to predict the evolution of damage obtaining a good correlation of results. Long and Aymerich [36-38] used cohesive solid and shell elements for the modelling of the interface of laminate in impact tests to obtain a fitting of delamination in graphite/epoxy 
specimens. The weakness of this procedure is the computational costs that are very expensive. In order to decrease the analysis time, a tiebreak contact approach for the interface model and to obtain delamination's data is used by Berk [39]. From the literature appears that among different available research works that aim on the study of FE model to predict the mechanical behavior of natural fibers or hybrid composite, no one focused the attention on the study of the impact behavior of on carbon/hemp fibers hybrid with a prevision of damage evolution and a clear explication of the modelling methodology.

On the basis of these considerations, the aim of this work is to develop reliable numerical models using Ls-Dyna in order to predict the impact response in terms of impact strength, adsorbed energy and interlaminar damage of an hybrid system that combine the ductility of hemp fibres with the strength of carbon fibres.

\section{Materials and methods}

\subsection{Materials and sample manufacturing}

Woven hemp fabric with an areal density of $160 \mathrm{~g} / \mathrm{m}^{2}$ (supplied by Maeko Srl) and T300 woven carbon fabric with an areal density of $200 \mathrm{~g} / \mathrm{m}^{2}$ (supplied by Toray international Srl) were used in this work to produce pure hemp, pure carbon and hybrid composite system using an epoxy resin (SX10 supplied by d by Mates Srl) as matrix. All composite laminate typologies were manufactured by the combination of hand lay-up and vacuum compression molding technique using a mold sized $300 \times 300 \mathrm{~mm} 2$. The cure process was made in a hydraulic press with a pressure of 8 bar and an initially controlled temperature of $55^{\circ} \mathrm{C}$ for two hour and subsequently 24 hours at room temperature. Carbon laminate (CFRP) is constituted from 15 plies of 0/90 fabric; hemp (HFRP) and hybrid (CHFRP) laminates were produced with the same numbers of plies. CHFRP laminate were manufactured by substituting three carbon plies with three hemp fabric layers, which are placed in the middle of the laminate as shown in Fig. 1

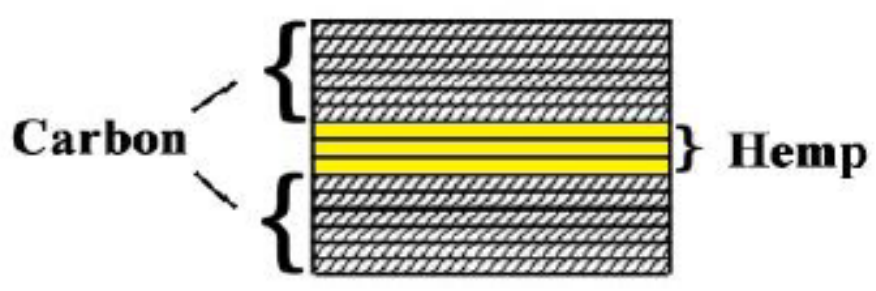

Fig.1 Hybrid laminate stacking sequences.

\subsection{Impact test}

Impact tests at 10J and 20J were carried out using a homemade machine with a mechanism of drop weight equipped with an impactor tip of $16 \mathrm{~mm}$ of diameter and a mass of $2.66 \mathrm{Kg}$. ASTM D7136 were taken as reference to perform the tests, then five rectangular specimens with a dimension of $100 \times 150 \mathrm{~mm}^{2}$ for each typology were tested. The specimens were clamped between two steel plates in order to avoid movement of samples. The acquisition method consisted in the use of a piezoelectric load cell and an amplificatory connected to a Personal Computer.

\subsection{Numerical Model}

Low velocity impact tests were simulated with the LS-Dyna software using the explicit solver. The FE model was 
reproduced considering the geometrical and load system symmetry, so only a quarter of the entire model was considered (see Figure 2). In order to obtain significative data concerning the damage evolution and its extent, appropriate material cards and damage models were considered. At this aim, in the present FE models, tiebreak contact was used in order to consider interlayer damage growth to allow the occurring of delaminations. In order to reproduce a reliable but fast FE models, shell elements were used to model the laminates using the mesh refining in the impacted region in order to obtain a fine mesh in the most critical region.

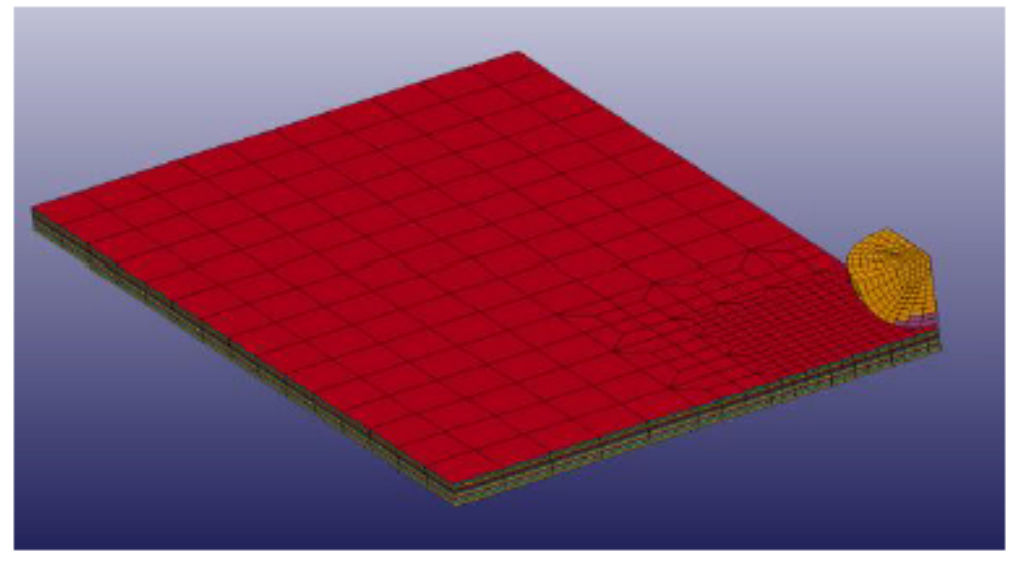

Fig. 2. Finite element geometry model.

Mat 54/55 (Mat_Enhanched_Composite_Damage) material card was used to simulate carbon layers, this material card is only valid for shell elements; while hemp layers were modelled with Mat 24 Card (Mat_Piecewise_Linear_Plasticity).

According to available literature, this material card is the best one for fitting the plastic behavior of natural fibers like hemp or flax [35]. Moreover, before to perform the impact simulations, both experimental and simulated tensile tests on HFRP specimens were carried out in order to validate the adopted material card for the hemp composite. The FEM model of tensile specimens has the same dimension of real specimens (100 $\mathrm{mm} \times 16 \mathrm{~mm} \times 3.7 \mathrm{~mm})$, modelled with shell elements. In the impact simulation the puncher was realized with solid elements using Mat 001 (Mat_Elastic) as material card. The puncher has a diameter of $15 \mathrm{~mm}$ and an initial velocity of $2742 \mathrm{~mm} / \mathrm{sec}$ to obtain the impact energy of 10 J and $3880 \mathrm{~mm} / \mathrm{sec}$ for the impact energy of 20J. An interlocking boundary condition was used to simulate the locking plate.

The element formulation is the constant Stress (ELEFORM 1) for solid elements and Hughes-Liu formulation (ELEFORM 11) for shell elements. Fibers crashing routine is simulated with a Chang-Chang criterion [40].

\section{Results and Discussion}

The results of both numerical and experimental tensile tests carried out on HFRP specimens are shown in Fig.3. In Fig.3a are depicted a typical image of the FEM model and in Fig. $3 \mathrm{~b}$ the comparison between numerical and experimental stress-strain curves are plotted. From the comparison appears that MAT 24 allows a good fitting with the experimental data and then it can be considered a suitable material card to simulate the hemp composite behavior, at least for quasi-static scenario. 
a)

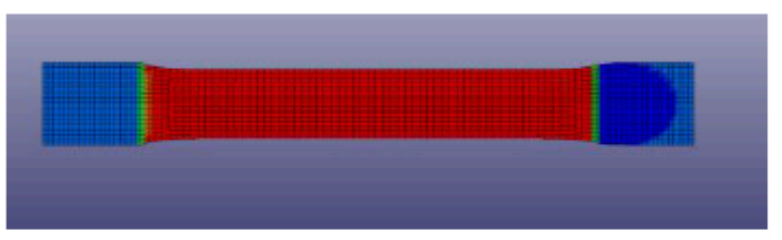

b)

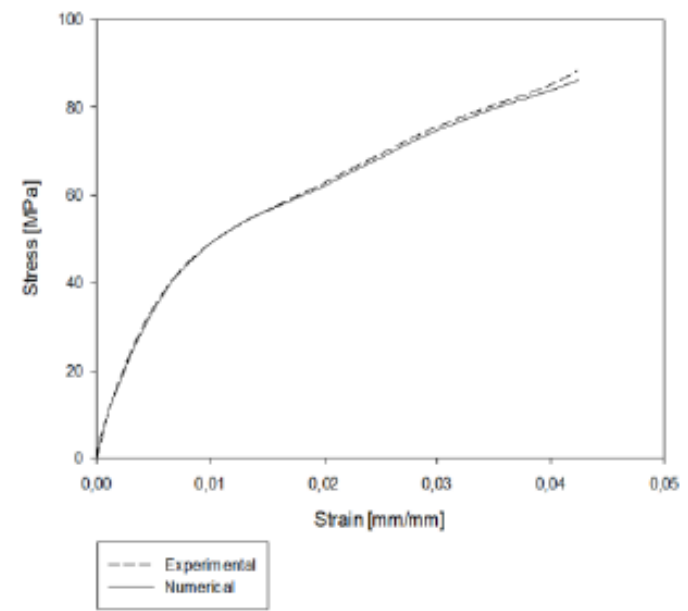

Fig.3. (a) FE model geometry of tensile tests and (b) comparison between numerical and experimental stress-strain curves.

The simulated response of laminate was analyzed by comparing the numerical load-time curves with the experimental ones. Figure 4 shows the comparison between load-time curves for carbon fiber laminate at $10 \mathrm{~J}$ and $20 \mathrm{~J}$. The results highlighted that the numerical peak load was very close to the experimental one and similar considerations can be done about the adsorbed energy. The only significative difference can be observed immediately after the peak load when the impact test at 20J is considered (Figure 4b). Here, the experimental specimen showed a rupture in the $\mathrm{z}$ direction of laminate that cannot be reproduced using shell elements, in fact they do not fully consider the third dimension. Differently, a perfect match can be observed in Figure 4a, it represents the curves for carbon laminate impacted at $10 \mathrm{~J}$.

a)

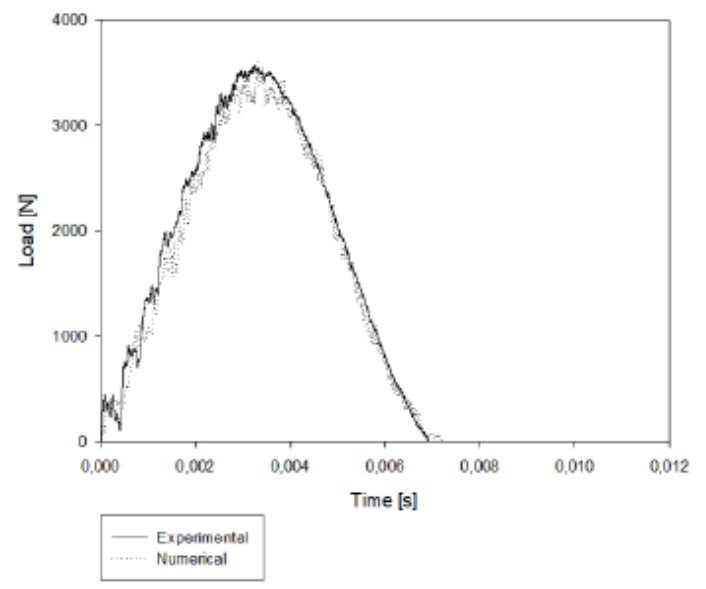

b)

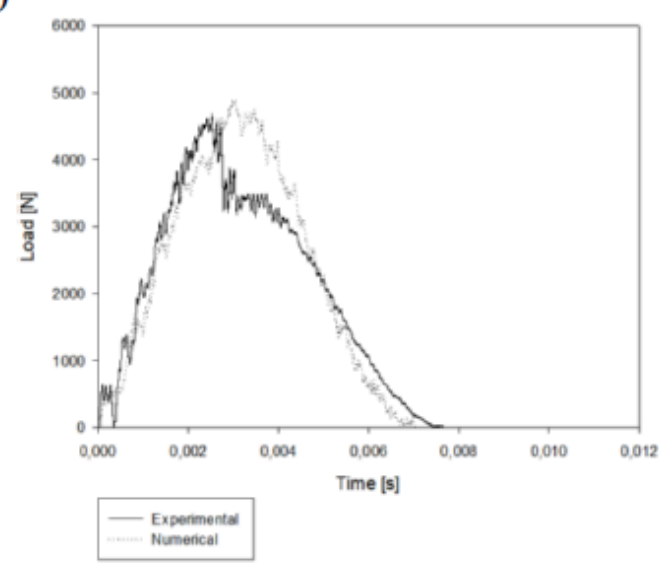

Fig.4. Comparison between experimental and numerical load-time curves at (a) 10J and (b) 20J on CFRP laminates.

Considering hemp laminate, the selected material card (MAT 24), generated a good fitting between experimental and numerical impact curves for both 10J and 20J as shown in Figure 5. 
a)

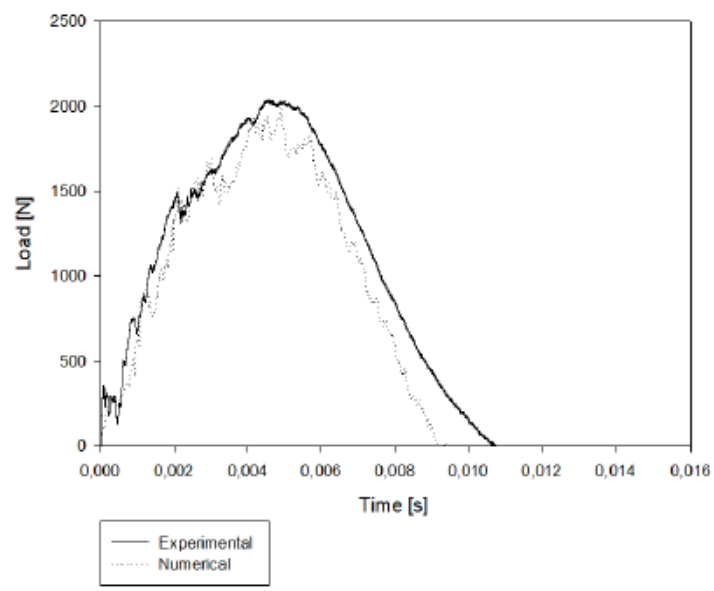

b)

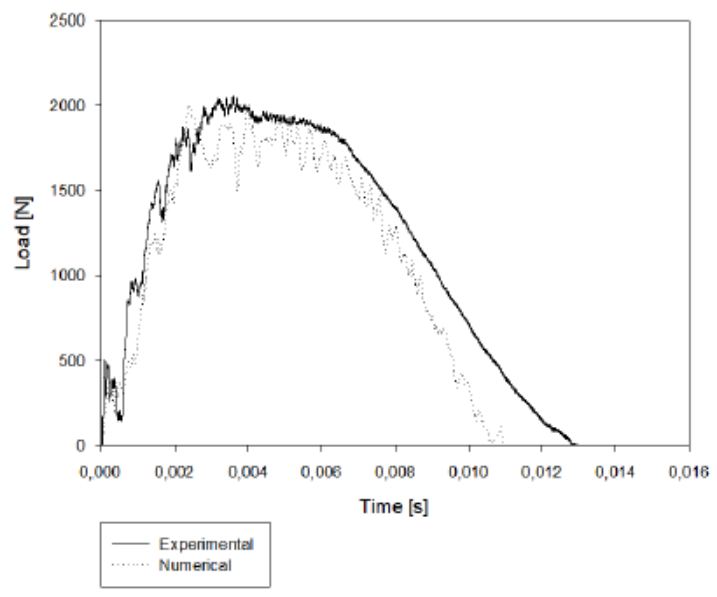

Fig.5. Comparison between experimental and numerical load-time curves at (a) 10J and (b) 20J on HFRP laminates.

The small difference can be observed in the elastic return region after the reaching of the peak load more than in the upload region. This can be due to the use of shell elements, as above discussed, and MAT 24 material card that is usually for isotropic materials whereas the used hemp fabric has an orthotropic behavior. A combination of carbon and hemp laminate using both, MAT 54/55 and MAT 24 cards, allowed the simulation of the hybrid laminate. Form Fig.6, it is possible to note that the numerical model reproduces very well the experimental behavior when the impact energy of $10 \mathrm{~J}$ is considered. The mismatch appeared more evident when the impact energy increases at 20J. The occurring of crash plies was not reproduced very well because shell elements do not reproduce the third dimension. In this case, the error of the peak load and of the adsorbed energy reached the highest values.

a)

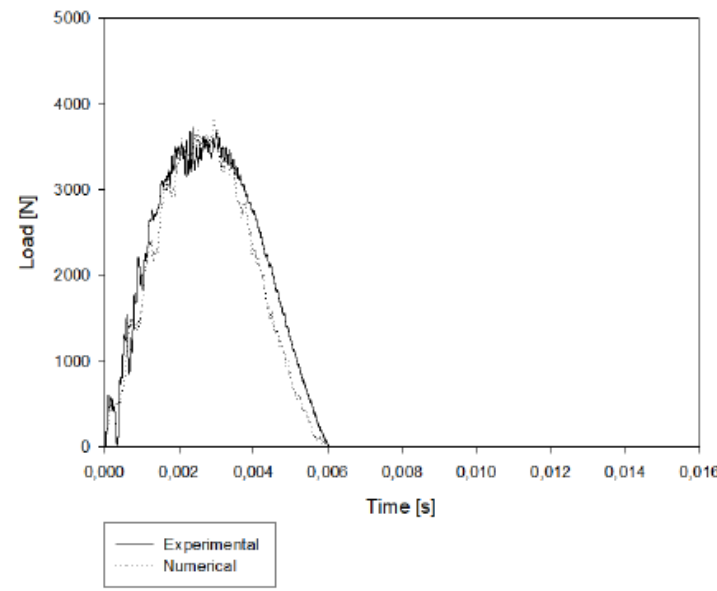

b)

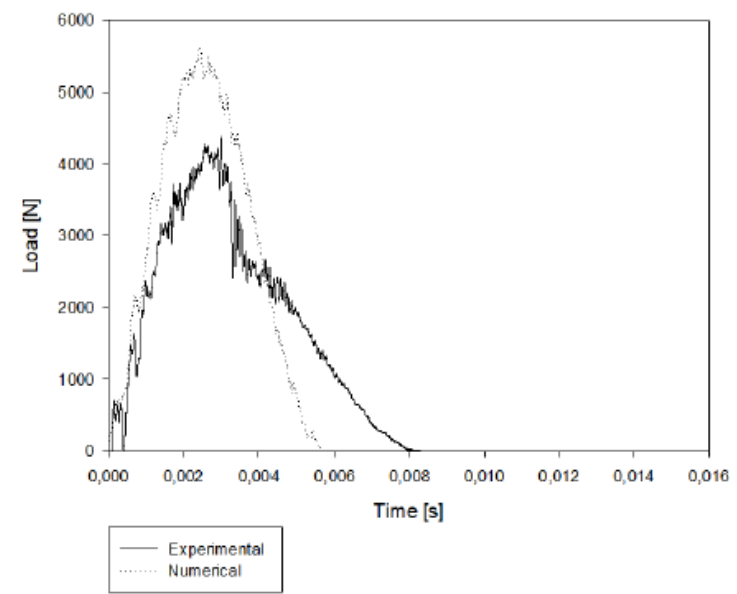

Fig.6. Comparison between experimental and numerical load-time curves at (a) 10J and (b) 20J on CHFRP laminates.

About the damaged occurred during the impact event, it can be seen from Table 1 that the prediction of the numerical model about the delamination extent showed a very good approximation with the results obtained from the C-Scan analyses. By way of example in Figure 7 it is reported the images carried out from the C-Scan analyses and the three layers of the FE models for hybrid sample type. In the FE model, the delaminated area was marked with red color and adding layer by layer its extent by using a Matlab routine, the total damaged area extent was evaluated and reported 
in Table 1.

Table 1. Damaged area extent: comparison between numerical and experimental results carried out by C-Scan analyses.

\begin{tabular}{cccc}
$\begin{array}{c}\text { Specimen } \\
\text { type }\end{array}$ & $\begin{array}{c}\text { Impact } \\
\text { Energy } \\
(\mathbf{J})\end{array}$ & $\begin{array}{c}\text { Experimental } \\
\text { damaged } \\
\text { area }\left(\mathbf{m m}^{2}\right)\end{array}$ & $\begin{array}{c}\text { Numerical } \\
\text { damaged } \\
\text { area } \\
\left(\mathbf{m m}^{2}\right)\end{array}$ \\
\hline CFRP & $10 \mathrm{~J}$ & 220.2 & 253.2 \\
CFRP & $20 \mathrm{~J}$ & 472.8 & 506.24 \\
HFRP & $10 \mathrm{~J}$ & 822.2 & 796.49 \\
HFRP & $20 \mathrm{~J}$ & 3060.8 & 2983.21 \\
CHFRP & $10 \mathrm{~J}$ & 446.6 & 415.22 \\
CHFRP & $20 \mathrm{~J}$ & 687.1 & 664.76 \\
\hline
\end{tabular}
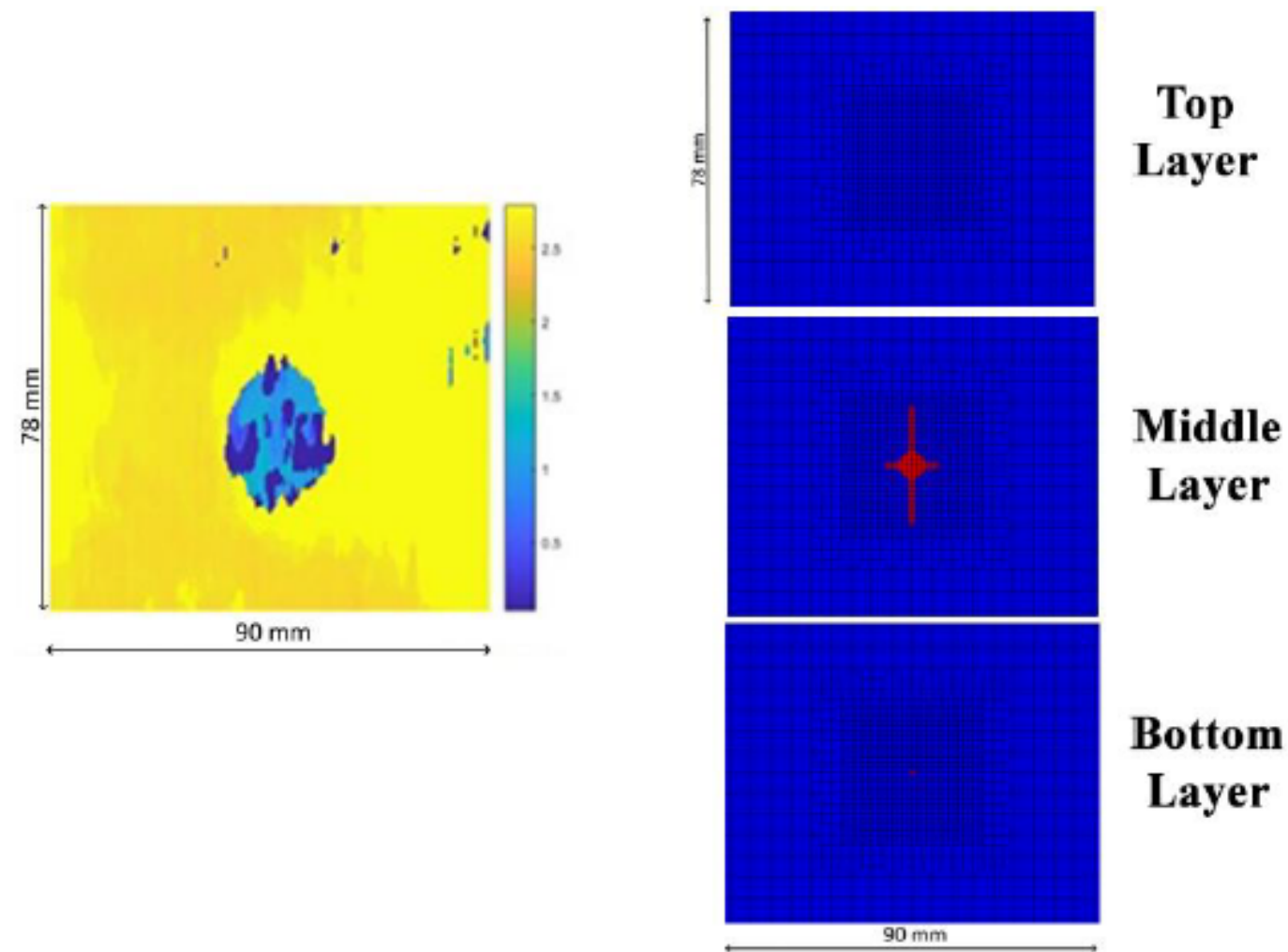

Fig. 7. Comparison of C-Scan of experimental specimen (on the left) and three layers of simulated one (on the right) for the hybrid laminate impacted with $20 \mathrm{~J}$ energy.

From both numerical and experimental results appeared that the HFRP sample showed the smallest delamination 
value and limited crack growth; differently from pure carbon laminate [14], the use of natural fibers in a hybrid system with carbon allowed to stop the cracking propagation.

\section{Conclusions}

This work investigated the possibility to use hemp fibers to produce hybrid carbon composite system developing reliable FEM models to predict the impact behavior. The results proved that the hybridization process is able to modify the impact response improving the adsorbed energy capability and decreasing the delamination extension respect to pure carbon laminate. The results of the FE models using Ls-Dyna software, proved that the use of shell elements can provide a valid solution to produce FE models with an acceptable computational cost obtaining results with a good fitting with the experimental tests. Also the delamination results seem to be in accordance with the experimental damage analyses and this brings a good innovation in the prediction of impact response and crack evolution. Therefore, the proposed FE models can represent a good approach to predict in a reliable way the impact behavior in terms of deformation, load and delamination damage of future laminates having the hemp layers in different positions within the laminate thickness.

\section{Bibliography}

[1] P. Beardmore, C.F. Johnson, The potential for composites in structural automotive applications, Compos. Sci. Technol. 26 (1986) 251-281. https://doi.org/10.1016/0266-3538(86)90002-3.

[2] L.Z. Linganiso, R.D. Anandjiwala, 4 - Fibre-reinforced laminates in aerospace engineering, in: S. Rana, R. Fangueiro (Eds.), Adv. Compos. Mater. Aerosp. Eng., Woodhead Publishing, 2016: pp. 101-127. https://doi.org/https://doi.org/ 10.1016/B978-0-08-100037-3.00004-3.

[3] J. Summerscales, D. Short, Carbon fibre and glass fibre hybrid reinforced plastics, Composites. 9 (1978) 157-166. https://doi.org/10.1016/0010-4361(78)90341-5.

[4] G. Kretsis, A review of the tensile, compressive, flexural and shear properties of hybrid fibre-reinforced plastics, Composites. 18 (1987) 13-23. https://doi.org/10.1016/0010-4361(87)90003-6.

[5] M.M. Stevanović, T.B. Stecenko, Mechanical behaviour of carbon and glass hybrid fibre reinforced polyester composites, J. Mater. Sci. 27 (1992) 941-946. https://doi.org/10.1007/BF01197646.

[6] D.K. Jesthi, R.K. Nayak, Improvement of mechanical properties of hybrid composites through interply rearrangement of glass and carbon woven fabrics for marine application, Compos. Part B Eng. 168 (2019) 467-475. https://doi.org/ 10.1016/j.compositesb.2019.03.042.

[7] P. Hung, K. Lau, L. Cheng, J. Leng, D. Hui, Impact response of hybrid carbon/glass fibre reinforced polymer composites designed for engineering applications, Compos. Part B Eng. 133 (2018) 86-90. https://doi.org/10.1016/ j.compositesb.2017.09.026.

[8] S. Mishra, A.. Mohanty, L.. Drzal, M. Misra, S. Parija, S.. Nayak, S.. Tripathy, Studies on mechanical performance of biofibre/glass reinforced polyester hybrid composites, Compos. Sci. Technol. 63 (2003) 1377-1385. https://doi.org/ 10.1016/S0266-3538(03)00084-8.

[9] S.. Joshi, L.. Drzal, A.. Mohanty, S. Arora, Are natural fiber composites environmentally superior to glass fiber reinforced composites?, Compos. Part A Appl. Sci. Manuf. 35 (2004) 371-376. https://doi.org/10.1016/ j.compositesa.2003.09.016. 
[10] G. Cicala, G. Cristaldi, G. Recca, G. Ziegmann, A. El-Sabbagh, M. Dickert, Properties and performances of various hybrid glass/natural fibre composites for curved pipes, Mater. Des. 30 (2009) 2538-2542. https://doi.org/10.1016/ j.matdes.2008.09.044.

[11] R. Sepe, F. Bollino, L. Boccarusso, F. Caputo, Influence of chemical treatments on mechanical properties of hemp fiber reinforced composites, Compos. Part B Eng. 133 (2018) 210-217. https://doi.org/10.1016/j.compositesb.2017.09.030.

[12] L. Boccarusso, L. Carrino, M. Durante, A. Formisano, A. Langella, F. Memola Capece Minutolo, Hemp fabric/epoxy composites manufactured by infusion process: Improvement of fire properties promoted by ammonium polyphosphate, Compos. Part B Eng. 89 (2016) 117-126. https://doi.org/10.1016/j.compositesb.2015.10.045.

[13] L. Boccarusso, M. Durante, A. Langella, Lightweight hemp/bio-epoxy grid structure manufactured by a new continuous process, Compos. Part B Eng. 146 (2018) 165-175. https://doi.org/10.1016/j.compositesb.2018.04.009.

[14] F. Pinto, L. Boccarusso, D. De Fazio, S. Cuomo, M. Durante, M. Meo, Carbon/hemp bio-hybrid composites: Effects of the stacking sequence on flexural, damping and impact properties, Compos. Struct. 242 (2020) 112148. https://doi.org/10.1016/j.compstruct.2020.112148.

[15] J. Zhang, K. Chaisombat, S. He, C.H. Wang, Hybrid composite laminates reinforced with glass/carbon woven fabrics for lightweight load bearing structures, Mater. Des. 36 (2012) 75-80. https://doi.org/10.1016/j.matdes.2011.11.006.

[16] C. Fragassa, Effect of natural fibers and bio-resins on mechanical properties in hybrid and non-hybrid composites, in: 2016: p. 020118. https://doi.org/10.1063/1.4949693.

[17] F. Sarasini, J. Tirillò, S. D’Altilia, T. Valente, C. Santulli, F. Touchard, L. Chocinski-Arnault, D. Mellier, L. Lampani, P. Gaudenzi, Damage tolerance of carbon/flax hybrid composites subjected to low velocity impact, Compos. Part B Eng. 91 (2016) 144-153. https://doi.org/10.1016/j.compositesb.2016.01.050.

[18] S.N.A. Safri, M.T.H. Sultan, M. Jawaid, K. Jayakrishna, Impact behaviour of hybrid composites for structural applications: A review, Compos. Part B Eng. 133 (2018) 112-121. https://doi.org/10.1016/j.compositesb.2017.09.008.

[19] M. Indra Reddy, M. Anil Kumar, C. Rama Bhadri Raju, Tensile and Flexural properties of Jute, Pineapple leaf and Glass Fiber Reinforced Polymer Matrix Hybrid Composites, Mater. Today Proc. 5 (2018) 458-462. https://doi.org/ 10.1016/j.matpr.2017.11.105.

[20] A. Murdani, S. Hadi, U.S. Amrullah, Flexural Properties and Vibration Behavior of Jute/Glass/Carbon Fiber Reinforced Unsaturated Polyester Hybrid Composites for Wind Turbine Blade, Key Eng. Mater. 748 (2017) 62-68. https://doi.org/10.4028/www.scientific.net/KEM.748.62.

[21] M. Cheng, Y. Zhong, U. Kureemun, D. Cao, H. Hu, H.P. Lee, S. Li, Environmental durability of carbon/flax fiber hybrid composites, Compos. Struct. 234 (2020) 111719. https://doi.org/10.1016/j.compstruct.2019.111719.

[22] M. Assarar, W. Zouari, H. Sabhi, R. Ayad, J.-M. Berthelot, Evaluation of the damping of hybrid carbon-flax reinforced composites, Compos. Struct. 132 (2015) 148-154. https://doi.org/10.1016/j.compstruct.2015.05.016.

[23] M.O.W. Richardson, M.J. Wisheart, Review of low-velocity impact properties of composite materials, Compos. Part A Appl. Sci. Manuf. 27 (1996) 1123-1131. https://doi.org/10.1016/1359-835X(96)00074-7.

[24] M.V. Hosur, M. Adbullah, S. Jeelani, Studies on the low-velocity impact response of woven hybrid composites, Compos. Struct. 67 (2005) 253-262. https://doi.org/10.1016/j.compstruct.2004.07.024. 
[25] V. Fiore, G. Di Bella, A. Valenza, Glass-basalt/epoxy hybrid composites for marine applications, Mater. Des. 32 (2011) 2091-2099. https://doi.org/10.1016/j.matdes.2010.11.043.

[26] S.Z.H. Shah, S. Karuppanan, P.S.M. Megat-Yusoff, Z. Sajid, Impact resistance and damage tolerance of fiber reinforced composites: A review, Compos. Struct. 217 (2019) 100-121. https://doi.org/10.1016/j.compstruct.2019.03.021.

[27] P.O. Sjoblom, J.T. Hartness, T.M. Cordell, On Low-Velocity Impact Testing of Composite Materials, J. Compos. Mater. 22 (1988) 30-52. https://doi.org/10.1177/002199838802200103.

[28] G.A. Schoeppner, S. Abrate, Delamination threshold loads for low velocity impact on composite laminates, Compos. Part A Appl. Sci. Manuf. 31 (2000) 903-915. https://doi.org/10.1016/S1359-835X(00)00061-0.

[29] C. Garnier, M.-L. Pastor, F. Eyma, B. Lorrain, The detection of aeronautical defects in situ on composite structures using Non Destructive Testing, Compos. Struct. 93 (2011) 1328-1336. https://doi.org/10.1016/j.compstruct.2010.10.017.

[30] R. Růžek, R. Lohonka, J. Jironč, Ultrasonic C-Scan and shearography NDI techniques evaluation of impact defects identification, NDT E Int. 39 (2006) 132-142. https://doi.org/10.1016/j.ndteint.2005.07.012.

[31] T. Hasiotis, E. Badogiannis, N.G. Tsouvalis, Application of Ultrasonic C-Scan Techniques for Tracing Defects in Laminated Composite Materials, Strojniški Vestn. - J. Mech. Eng. 2011 (2011) 192-203. https://doi.org/10.5545/ sv-jme.2010.170.

[32] C.C. Tsao, H. Hocheng, Computerized tomography and C-Scan for measuring delamination in the drilling of composite materials using various drills, Int. J. Mach. Tools Manuf. 45 (2005) 1282-1287. https://doi.org/10.1016/ j.ijmachtools.2005.01.009.

[33] J. He, L. He, B. Yang, Analysis on the impact response of fiber-reinforced composite laminates: an emphasis on the FEM simulation, Sci. Eng. Compos. Mater. 26 (n.d.) 1-11. https://doi.org/https://doi.org/10.1515/secm-2017-0222.

[34] G.S. Dhaliwal, G.M. Newaz, Experimental and numerical investigation of flexural behavior of carbon fiber reinforced aluminum laminates, J. Reinf. Plast. Compos. 35 (2016) 945-956. https://doi.org/10.1177/0731684416632606.

[35] K. Ramakrishnan, S. Corn, N.L. Moigne, P. Slangen, LOW VELOCITY IMPACT DAMAGE ASSESSMENT IN NATURAL FIBRE BIOCOMPOSITES, in: 2017. [36] S. Long, X. Yao, X. Zhang, Delamination prediction in composite laminates under low-velocity impact, Compos. Struct. 132 (2015) 290-298. https://doi.org/https://doi.org/10.1016/ j.compstruct.2015.05.037.

[37] F. Aymerich, F. Dore, P. Priolo, Prediction of impact-induced delamination in cross-ply composite laminates using cohesive interface elements, Compos. Sci. Technol. 68 (2008) 2383-2390. https://doi.org/https://doi.org/10.1016/ j.compscitech.2007.06.015.

[38] D. Feng, F. Aymerich, Finite element modelling of damage induced by low-velocity impact on composite laminates, Compos. Struct. 108 (2014) 161-171. https://doi.org/10.1016/j.compstruct.2013.09.004.

[39] B. Berk, R. Karakuzu, B. Murat Icten, V. Arikan, Y. Arman, C. Atas, A. Goren, An experimental and numerical investigation on low velocity impact behavior of composite plates, J. Compos. Mater. 50 (2016) 3551-3559. https://doi.org/10.1177/0021998315622805.

[40] F.-K. Chang, K.-Y. Chang, A Progressive Damage Model for Laminated Composites Containing Stress Concentrations, J. Compos. Mater. 21 (1987) 834-855. https://doi.org/10.1177/002199838702100904. 
PDF automatically generated on 2021-05-23 09:38:56

Article url: https://popups.uliege.be/esaform21/index.php?id=2651

published by ULiège Library in Open Access under the terms and conditions of the CC-BY License (https://creativecommons.org/licenses/by/4.0) 